This is a self-archived final draft version of the original article. It may differ from the original in pagination and typographic detail.

Cite

Zechner, M. 2017. Transnational habitus at the time of retirement. Identities 24 (5), 573-589. DOI:10.1080/1070289X.2017.1345543

To link to this article:

https://doi.org/10.1080/1070289X.2017.1345543

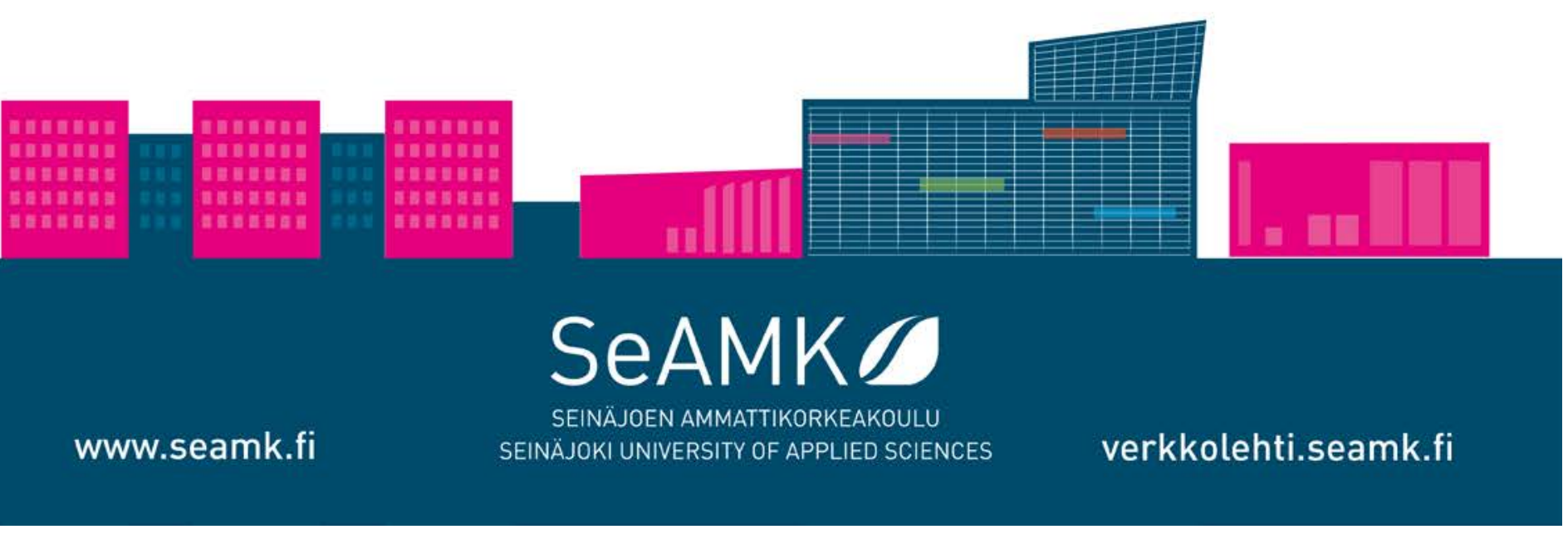




\section{Transnational Habitus at the Time of Retirement}

Identities. Global Studies in Culture and Power 24(5), 573-589.

\section{http://www.tandfonline.com/doi/full/10.1080/1070289X.2017.1345543}

Abstract:

International mobility requires the shifting of bodies across places, through life courses and stages, creating individual and collective experiences that become taken for granted. They are habitus, which is the durable deployment of an individual's body in the world, as well as a scheme of perception, thought and action that is present throughout life, including retirement. This study asks what kind of transnational habitus is visible in the narratives of interviewed older adults at the time of retirement. The answer is sought by analysing life stories of mobility from older adults who live or have lived abroad for several years. The multilocal transnational habitus of interviewees rests on their desire to maintain their mobility when retired. However, both their physical and mental international mobility is at risk when faced with an ailing body and mind, and policies allow and restrict the transferability of benefits and accessibility to services.

Key words:

habitus, transnational, retirement, migration, life story, social field Word count including everything but the title page: 7170 


\section{Transnational Habitus at the Time of Retirement}

Minna Zechner, Seinäjoki University of Applied Sciences

minna.zechner@seamk.fi

In this article, I present an analysis of life stories of mobility from older adults who live or have lived abroad for between 13-52 years. Their experiences of international migration are incorporated in their habitus, which is a product of person's history, social position, perception and symbolic mastery (Bourdieu 1977). I ask what kind of transnational habitus is visible in the narratives of the interviewees at the time of retirement. For data, I use life stories of mobility in which eight white Europeans or North American interviewees aged 60 and over explain the major international mobilities. Their past, present and future lives are transnational, which refers to relationships, activities, affiliations and social formations, which span nation-states (Vertovec 2009, 2).

International mobility requires the shifting of bodies not only across places, but also through life courses and stages, creating histories that are both individual and collective (see Gardner 2002, 1). These experiences that become taken for granted are part of habitus, which is the durable organization of an individual's body and its deployment in the world. Habitus is also a scheme of perception, thought and action (Bourdieu 1989, 14) which is present throughout life, including the age of retirement. Retirement is different for migrants than for non-migrants because many migrate for employment and retirement takes away this reason to stay (Bolzman, Fibbi and Vial 2006, 1360). However, many migrants choose to stay when retiring, even when the link between income and the place of residence has weakened (Klinthäll 2014, 22).

Return of retirement or return migration of pensioners refers to retired migrants who decide to return to their place of origin, notwithstanding their reasons for migration (Klinthäll 2014). 
Retirement migration is a concept used to describe the seasonal or permanent move of retired and in many cases affluent individuals (Oliver 2008). Finally, lifestyle migration is defined as the migration of rather affluent individuals, moving temporarily or permanently to places that for various reasons signify improved quality of life for the migrants (Benson 2012). When the relationship to one’s body changes simultaneously both physically (with bodily ageing and ailments) and societally (being retired), then individuals may reconsider their place of residence. This creates a good momentum to study transnational habitus.

\section{Transnational Habitus}

Pierre Bourdieu's $(1989,14)$ theory of human social practice gives equal weight to structure and agency, so that in the social world there are objective structures notwithstanding the consciousness and will of actors, who in turn, are able to guide and constrain their practices. The subjective side of actors is structured in terms of their 'schemes of perception, thought and action', which Bourdieu (1989, 14) calls habitus. Central to the concept of habitus is the internalization of social expectations and value systems, and their incorporation into bodily dispositions (Kelly and Lusis 2006, 834).

Habitus is the part of society that lives in the individual (incorporated history), while field represents social structures (objectified history). There are tensions and dialectical relationships between habitus and field (Bourdieu 1990, 66). Fields are delineated by sets of connections among objective positions that may be filled by individuals, groups or organizations, and the relationships among and between these positions are particularly important (Allan 2007, 420). Various types of capital power activities in these fields. 
The four forms of capital in Bourdieu’s $(1986,243)$ theory are economic, social, symbolic and cultural. Economic capital is determined by wealth and income, and it influences the levels of other capitals. Social capital is found in the individual's networks and connections, and can be mobilized to generate advantages or benefits (Bourdieu 1986, 249). Many migrants maintain strong links to their place of origin or places where they have lived or have meaningful contacts. These links are varied (e.g. economic, social, cultural, political, institutional or emotional), and they merge seamlessly into lived experiences that can be understood in the framework of habitus (Kelly and Lusis 2006, 831). Symbolic capital is the capacity to use symbols to create or consolidate physical and social realities (Bourdieu 1990, 166). Social categories such as migrant, ethnicity and gender are generated through symbolic capital.

The fourth type of capital is cultural, which refers to informal social skills, habits, linguistic styles and tastes. Bourdieu (1986, 243) distinguishes three types of cultural capital. Objectified cultural capital includes material goods such as books and artwork. Institutionalized cultural capital includes certifications, diplomas and degrees that officially acknowledge the possession of skills, knowledge and abilities. Embodied cultural capital is something that partly constitutes the habitus of an individual. It is lived and expressed through and by the body and is manifested in taste. Taste is strongly influenced by social class: those who recognize and follow a similar cultural code regarding, for example, travelling, clothing and housing.

These forms of capital are contingent in the sense that their valuation is determined within a particular social and spatial context (Kelly and Lusis 2006, 834). In some studies, habitus is considered as place-specific (cf. Bauder 2004), whereas others emphasize the transferability of habitus (cf. Kelly and Lusis 2006). International mobility presents situations where various types of capital might be lost or gained, and also offers opportunities to learn how to use them in various 
fields developing a transnational habitus. As a life-cycle transition, retirement is a time when one’s capital may be threatened, thereby triggering migration (O’Reilly 2014, 219). Individuals aspire to different sets of imaginations and have differing capacities to plan their future. However, imagination and the capacity to plan ahead are shaped externally. To understand and indicate transnational habitus in retirement plans and realizations, I analyse life stories that expose the process by which the imaginings that inspire mobility and migration are translated into practice. This is particularly appropriate as transnational habitus is present in the embodied interplay of biographies, individual circumstances, structural preconditions, privileges and constraints (Benson 2012, 1693).

\section{Analysing Life Stories of Mobility}

This study is based on seven life stories of mobility told through interviews with six women and two men aged between 60 and 87. The interviews lasted from 1.5 to 2 hours, and were conducted individually except for one in which a couple participated and produced a joint story. Two of the interviewees were Finns who had lived abroad, and six were non-Finns either living or having lived in Finland. Five were already retired, and the rest were working. The interviews were conducted in December 2014 and January 2015 in Finland, with one conducted online from Finland to the USA.

Migration and non-migration patterns tend to be a continuation or an extension of preretirement patterns (Böcker and Balkir 2016, 127); hence, it makes sense to simultaneously study those who have retired and those who have not yet retired. Most of the interviewees (five) lived in the socalled third age. For these cohorts who came of age in the 1960s or later, consumption and lifestyle rather than work and class identity are central to their habitus (see Skeggs 2004). Based on their age and their increasing need for help, three interviewees at least partly lived in the fourth age, and the 
difference between the third and fourth ages lies not only in the possession of resources, but also in the capacity of choosing how to use them (Gilleard and Higgs 2005).

All but one of the interviewees had a university-level education; one interviewee was single and had no children, and all but two interviewees had grandchildren. The interviewees were so-called privileged migrants who are European or North American professionals moving abroad (to Australia, Finland, Germany, Switzerland, United Kingdom), mostly for professional reasons (see Fechter and Walsh 2010, 1199). They were found through personal networks and using a snowballing technique. The criteria were that interviewees were at least 60 years old and had lived abroad for several years at some point in their lives.

Interviewees were purposely selected to avoid representing particular large migrant populations, (e.g. Mexicans in the U.S.) because most existing studies present older migrants by nationality, leading to an impression that national groups in certain countries are homogeneous (see Ciobanu and Ramos 2016). The aim was to include individuals whose international migration or mobility had occurred at differing stages of life, and to consider their entire migration history. Both migration and retirement are major transition processes, not only situated in historical, economic and policy contexts, but also related to social positioning, and hence to habitus (see Karl and Ramos 2016, 119).

Interview questions included background information (age, citizenship, education, income level, occupation, employment and family members), the times and reasons for living abroad through the interviewee's life, and a number of questions related to retirement (timing, where to settle and why). Narratives are accounts of oneself and one's experiences but also of particular social situations and physical spaces in which these experiences occur (Ferrell 2012, 225). Hence, the interviewees were 
encouraged to tell their stories as they wished, thereby constructing personal narratives that are useful for exploring life events and for understanding tastes, attitudes and behaviours - habitus.

As a result of personal life histories and unique experiences, individuals internalize different sets of structures and norms. Personal histories are created through actions to which imagination is a predecessor. Social imagination is the individual capacity to imagine life in different places and the possibility for enacting those imaginations (O’Reilly 2014, 223). In a way, imagination is a type of habitus, produced through one’s life stories (Benson 2012). Everyday transnational practices, taking place across two or more settings, have lasting impacts on individuals and their perception of the world, thus making the repertoires of habitus multiple and complex (Vertovec 2009, 25, 64).

The life stories of mobility spanned from childhood experiences to the present. This analysis focuses on major events in each life story that generated rich descriptions. These events can be epiphanies that are often seen as turning points in narrated life stories (Denzin 1989). However, major events may also be episodic, small events that contain detailed descriptions and visualizations (see Brewer 1986). Thus, this analysis emphasizes the interpretations and meanings that the interviewees themselves place on mobility and migration as part of their stories and choices. This is useful in studying habitus because habitus naturalizes the attitudes and behaviours of people with similar backgrounds, and makes them appear obvious (Richardson and Skott-Myhre 2012, 11). As habitus is consolidated throughout life, life stories have the potential to provide fruitful data for its study.

\section{Transnational Retirement: 'I'm Just Afraid of the Day When I Have to Decide'}

\section{The Beginning of Mobility}

There are two main ways to start a life story of mobility. For some, an interest in travelling, languages and other cultures was a natural stepping stone towards international mobility and 
migration. For others, moving abroad was a new direction in life. Kate is 63-year-old American woman who lived in Finland for 26 years with her husband and two sons. After being widowed for two years, she returned to the United States in 2014 and now lives near her adult sons and their families. She intended to retire before moving back to the U.S., but her employer offered a chance to work remotely, in order to finish her ongoing projects. While working, she also babysits her 9month-old granddaughter. Her mother is deceased, but her frail father (92) lives a four-hour drive away.

Kate noted that: “It wasn't a natural thing for us that we would just suddenly go to Finland, because we lived in Australia last year, and we wanted to try Botswana next year.” However, she and her husband had previously visited and worked some time in Finland, and had connections that were helpful in finding jobs for both of them. Migrants, (particularly those who are highly skilled) form their habitus based on their experience of mobility and a mixture of local, national and cosmopolitan cultural references; so becoming rooted in an 'on the move' lifestyle (Nedelcu 2012, 1346). Kate did not emphasize their earlier trips to Finland to study and work. Instead, she constructed two types of transnational habitus; living abroad as a natural course of life, and moving abroad as what she termed as a "big leap”. She had already internalized a transnational habitus so that she was able to imagine moving to Finland, while externalizing the acts of those who might find these moves mundane. There is a dialectic nature between the internalization of externality and externalization of internality (Bourdieu 1977, 72) that influences the creation and nature of a collective habitus (Richardson and Skott-Myhre 2012, 13).

For Yasmine, international mobility was also a part of her identity and everyday life, due to her interest in other cultures and a dislike towards her own: "I was interested in other people’s points of view of life—not just the English one. Because I was born just before the war and all this patriotism 
and hating other people -I didn’t quite like it.” Yasmine is a 76-year-old British widow of ten years who studied for one year in Switzerland in the mid-fifties, lived in Australia with friends for one year at the end of the fifties, and who moved to Finland at the beginning of 1960s, where she still lives. Her husband was a Finn, and their two adult sons live in Finland, and are married with two children. Her parents are deceased.

Yasmine constructed her transnational habitus in opposition to patriotism and building barriers between nations and cultures. Transnational cultural capital (considered as intercultural competence and language proficiency: Gerhards and Hans 2013) indeed points to cooperation and networking, and transnational competence enables individuals to participate effectively in activities that cross national boundaries. These may include analytic, emotional, creative, communicative and functional competencies, each of which help to create a sense of openness and mutability (Vertovec 2009, 72).

\section{Attachments and Detachments: Children, Grandchildren, Languages and Culture}

There are strong connections between people’s lifetime 'activity spaces', the places where they have lived and visited for education, work, family reasons and holidays, and the places that they consider for residence in their retirement (Hall and Williams 2002). These 'activity spaces' influence considerations of where to retire to. None of the interviewees pictured moving to a place where they had no attachments, favouring places of previous residence, or locations near children or other family members. None had a second home for holidays or which they could use as a possible place for retirement. Second home ownership, seasonal migration and long-stay international tourism may constitute the first step towards permanent migration (Böcker and Balkir 2016), but this route was not chosen by the interviewees. Their realized or envisioned moves did not resemble lifestyle migration, although they often imagined themselves in places they saw as more or less suited to their age (see Gardner 2002, 21). 
Interviewees mainly imagined living in places with attachments such as children and grandchildren when they retired. Anne is a 60-year-old Finnish woman who lived for 19 years in Germany. She interrupted her high school, and went to work in Germany where she later studied and met her German husband. She left Finland in the mid-seventies and returned at the beginning of 1980s with her husband and their two daughters. Since then, she worked as a kindergarten teacher, an occupation from which she is due to retire in a few years. Her daughters are now students, and her husband has worked in various culture-related short-term jobs in Finland. Both of their sets of parents are deceased. Anne noted: “If you travel with your kids currently or have travelled with them during the last 20 years, they seem to keep the travelling mood.” Children grow up seeing international mobility, if not migration, as a normal part of life. The transmission of values and the inculcation of habitus increasingly tend to take place within deterritorialized contexts (Nedelcu 2012, 1345). In an ever-changing world, there are no longer ready templates for the identity construction of younger generations (White and Wyn 2004, 184). However, the interviewees seemed to be able to pass on mobility and transnationalism as part of their children's everyday life and identity building.

Engaging children with their mobile life may also be a source of guilt for parents. Learning languages, and seeing and pursuing opportunities across the globe is an inheritance that interviewees portray as having passed on to their children. However, this inheritance has a price tag since children need to make an extra effort to learn two or more sets of values, languages, habits and customs, and also become used to different climates and foods. These new ways of living have econsequences for the corporeal existence and everyday life of their children, moulding their habitus and cultural capital. Migration also influences parenting, as migrants may feel the need to combine two types of mothering (from previous and present home countries), while also attempting to increase children’s transnational competence, for example by encouraging a cosmopolitan 
worldview and intercultural communication skills (Nukaga 2012). In addition to transnational competence, children also need to learn the habits and traditions of the country where they grow up, and accumulate cultural capital that the parents may not accrue. For parents, this lack in cultural capital may hinder their access to social and healthcare services in old age (Reynolds and Zontini 2014). Ultimately, a conflict in embodied cultural capital (such as moral values) between countries of origin and residence may also prompt return migration at the time of retirement (Ciobanu and Ramos 2016, 98).

Mari is a 68-year-old Finnish woman who studied for one year in the United Kingdom in the midsixties. From there she moved to Germany, where she lived for 44 years until moving to Finland four years ago. She has a German husband who stayed in Germany and a son who lives next door to her with his wife and son. Mari stressed: "I have always said that I would never move back to Finland.” Having three major moves in her life story (to the United Kingdom, Germany and Finland), she has several places of attachment that contain personal, embodied experiences and memories from her everyday life at various stages. For her, the birth of a grandson and not home place nostalgia (see Attias-Donfut 2016, 91) was a decisive factor that made her change her mind about returning to Finland: "For me, it is people who are important, not so much the place. If they lived in Timbuktu, I would have moved there.” Notions of belonging, locality or community refer to both a demarcated physical space and to clusters of interaction (see Gupta and Ferguson 1992, 8).

It has been claimed that those who move in early adulthood detach themselves to some extent from their parents' and their siblings' generations, and a consequence of this is an attenuated kin support network in old age (Warnes et al. 2004, 316). Mari’s parents were deceased and she had no siblings, but she maintained a strong connection with her son. With all of the interviewees, the need for the support of younger generations rather than older generations was the main determinant of the 
residential distance between them and their adult children. Mari did mention that her son had promised to look after her in old age. Her primary motivation for moving may have been to sustain the close ties between her as a grandmother and her grandson, but her present and future needs for care also seem to have influenced her decision to move, especially because care for the elderly in Germany is family-based (Horn et al. 2016). Only one interviewee (Kate) who returned from Finland to the U.S. had a living parent. Her return was partly influenced by her father's worsening condition, yet she chose to settle close to her sons instead of her father - possibly anticipating her own future needs for care.

Non-resident members of the family constitute an important part of an individual's location-specific social capital. Interviewees had relatives and people close to them in various places in addition to their countries of origin and countries of present residence. As such, Bourdieu's theory of habitus needs to be revisited in the light of its territorial dimension (see also Nedelcu 2012, 1354). Transnational life-worlds and places of attachment are expanded by the mobilities of children and other confidants. Therefore, there is need to move beyond binaries (old and new, migrant and host) and more towards a sense of habitus as both transformed and transformative (Parker 2000, 75).

\section{Structures: Policies and Services}

Citizenship was an important topic of discussion in the life stories of mobility. Having lived abroad in past decades, interviewees were able to compare being a migrant in the past and in the present. James is 68-year-old American retiree who moved to Finland in the beginning of the seventies and still lives there with his Finnish wife, who is still working. Their parents are deceased, and their son and daughter are adults, both married with two children. He has a brother and sister in the U. S., and also another brother in Finland. James talked about the citizenship of his children: 
Finnish law said they had to be American, even if their mother was Finnish and they were born in Finland. However, that was changed in the mid-70s. So they became Finnish citizens right away, but they are still both American citizens.

Dual citizenship reflects a particular set of dualistic dispositions and the dual orientation of transnational habitus (see Guarnizo 1997, 311). In the extract, recollections of past regulations and legal frameworks show how fields in which the interviewees act (e.g. the labour market and migration policies) are changing. These changes are reflected in their everyday lives, and it is also possible to see that they interact with several fields of the same kind, at the same time. Citizenship shapes the transnational habitus in many ways by allowing and restricting certain rights and duties related to travelling (visas, passports, residence permits), as well as the access and conditions that relate to social and healthcare services and benefits. For example, income benefits may be nonexportable and contain restrictions relating to short term international mobility (Zechner 2010). Today, these fields are increasingly interconnected, complex and in a state of flux, and this influences the habitus of not only transnational individuals, but everyone.

Another example of a changing field comes from the American healthcare system. Kate returned to America after 26 years of living in Finland, and noted that: "It gets complicated, once you have lived outside the United States, to go back as far as taxes, administration and stuff like that are concerned.” Even economic capital (which is often considered the least contingent on location) may lose value when transferred elsewhere. Taxation registration and health insurance as economic capital are hard to transfer, depending on where it needs to be transferred to. For example, Mari returned from Germany to Finland, and could transfer her pension from her German account into her Finnish account easily and free of charge. It was helpful that her migration took place in the field of European policy-making that aims to facilitate the movement of certain individuals. 
Returning to Kate, recent changes in American healthcare policy were extremely important: “Once Obamacare passed, I'm able to get health insurance.” A decisive factor that made the move back to the U.S. possible was the Affordable Care Act (known as Obamacare), a policy reform that ensures that all legal American residents have health insurance (American Government) regardless of their income level. Her actions are anchored in the requirements of two differing healthcare insurance fields. The field of the American healthcare insurance system had changed, and symbolic capital was used by President Obama who pushed the healthcare reform through despite resistance. Kate had suffered from cancer and needed medical follow-up and possible treatment in the future. Like other migrants with chronic illnesses, Kate therefore tends to attach great importance to retaining access to healthcare services (Böcker and Balkir 2016, 133).

In addition to healthcare, the issue of income level in retirement was often raised during the interviews. Interviewees were not specifically concerned about their income, although they were aware that pensions are lower than salaries. Contrary to many labour migrants (see Himmelreicher and Keck 2016), the interviewees tended to have good pension rights. Phyllis (84) and Dylan (88) are American retirees who have lived in Finland for the last 13 years. They have a son and a daughter. The son lives nearby with his Finnish wife, and their son is studying in a Finnish university. Phyllis and Dylan’s son has another son from a previous marriage living in South America. Phyllis and Dylan have a daughter living in the U.S. who has two sons with four children (Phyllis and Dylan’s great-grandchildren). When asked how they cope, Phyllis recounted: “We’ve figured out many times that it surprisingly doesn’t cost us any more to live here than in the United States.” Dylan added that: 
Part of the reason why it doesn’t really cost us any more to live here than it did in the

United States is the health insurance we had that was much more expensive than here.

You pay more taxes here; we were paying close to $\$ 4000$ a year for health insurance. Phyllis and Dylan were able to draw on their economic and social capital, with the son living in Finland able to help them plan and realize the move. This planning included several calculations matching the cost of living to their incomes, showing that the American and Finnish fields of health insurance have differing logic but entailed approximately the same costs.

Economic capital is also important in care for the elderly, and the possible need for care in the future came up during the interviews. The unwillingness to become a burden to significant others was mentioned by Natalia, who is a 63-year-old American woman. She lived for two years in the United Kingdom in the mid-seventies and has lived in Finland since 1979. She is single, childless and has two brothers, one living in South America and the other in the U.S. Both of her parents are deceased. In Finland, she has worked for almost the entire 35 years as a university teacher. She noted: "I have this feeling that I would sort of like to be in the States where my family is, that somehow they could help me more than being a burden on some friends.” The need for care is portrayed as draining social capital, with a clear preference to rely on family members rather than friends. Natalia seems to think that in the field of care, economic capital can only compensate for a lack of social capital to a limited extent. She would prefer to be near her family in the U.S. rather than stay to draw on the predominantly publicly funded care services available in Finland.

Three of the eight interviewees mentioned that they need some help in their daily life, largely in regard to shopping, small repairs and handling paper work. Care capital can be divided into informal (family and friends) and formal (services) capital, and is particularly relevant in the lives of older adults who need assistance (Anttonen and Sipilä 2006). Social capital and informal care 
capital resemble one another, but formal care capital is a constellation mainly of economic, symbolic and cultural capital. Economic capital is needed if user fees apply in care services. Symbolic capital may include citizenship status as giving or restricting access to services, and cultural capital can consist of knowledge about services, the ways to access them, and also the ability to accept care given by professionals.

\section{The End of Mobility?}

Continuing international mobility is a common wish for all interviewees. As an American who lives in Finland, Natalia expressed that:

I have never thought I am here for the rest of my life. I would hope to be able to go back and forth as long as possible and I have always dreaded that day when I realize I can't do it anymore.

Most migrants choose to retire in their host country where children, grandchildren and services are often available (Fokkema, Cela, and Witter 2016, 146). Pendular or temporary migration in fact seems to be a permanent phenomenon, instead of a prelude to either a permanent return or an inability to decide where to stay (Hugo 2013, 3). Natalia's wish to commute represents the two capacities that define habitus: firstly, the capacity to produce classifiable practices of commuting, and secondly, the capacity to differentiate and appreciate these practices (see Bourdieu 1984, 170). Approaching retirement and the bodily decline that likely awaits when growing older will have an influence on Natalia's transnational practices. The opportunities and abilities to act in different fields and make use of capital may change when the body or mind become frail, ill, disabled and in need of care. To some extent, economic capital and transnational habitus as a skill, as well as the ability and perhaps the courage to detach oneself from some supporting structures such as healthcare services in a given place, may help to sustain mobility (cf. Böcker and Balkir 2016, 133). 
Access to mobility as a fundamental axis in class divisions (King 2012) may become less important at an advanced age, since at some point commuting and travel come to a halt.

As a Finn who returned from Germany after 44 years, Mari has already incorporated her inability to travel into her habitus. She said that "London is kind of my great love, but nowadays I am not up to travelling there any more, except in my thoughts”. When bodily decline limits travel and removes international mobility from everyday life, she takes refuge in the embodied cultural capital collected during the years when she was able to spend time in London. Although her physical mobility across international borders has ended, she still continues to be socially and mentally mobile through the use of photographs, social ties and memories (cf. Lean 2012).

Finally in the interviews, there was discussion surrounding death. Kate (an American who lived in Finland for 26 years) experienced an epiphany on reading a major Finnish newspaper:

I opened up the Helsingin Sanomat, and there was a big obituary for this person. I thought, oh my god, I know her! Her children and husband had gone back to the U.S. years ago, and she had been in Finland all that time. She was just a year older than me. You know, she died at a hospital, and I knew she died alone.

This revelation triggered Kate's plans for a major move back to the U.S. She wanted to avoid the risk related to transnational habitus, that with a globally dispersed social capital, she may end up spending the end of her life far away from family members and friends. This risk is very much present for those who have no children (such as Natalia), and who face difficulties in weighing attachments when considering where to reside when they are retired. As Americans living in Finland, James, Phyllis and Dylan also have to find a balance between the various places where their children live, and where they themselves have lived, live and wish to live in the future. 
Communication technologies allow a degree of social support from afar, but physical care requires proximity (Zechner 2008). The issue of death has not attracted very much attention in studies on migration (see however Ackers and Dwyer 2002), and not even in studies on transnational care for the elderly.

\section{Conclusions}

This analysis has shown that individuals of varied nationalities may share similar life stories, experiences, appreciations, attachments, privileges, life goals, and also the creation of a transnational habitus. Studying older adult's life stories of mobility reveals some of the events and circumstances that form principles and situations that become naturalized and subsequently unrecognized to transnational individuals (see Bourdieu 1977, 12). Life stories as data are helpful in revealing the accumulation and continuity of transnational habitus from youth to the age of retirement, and even passing it on to younger generations.

At the same time, life stories of mobility challenge the often-assumed bi-focality seen in transnational habitus (for example Vertovec 2009) by showing that at the time of retirement, transnational individuals have created attachments to many places. A transnational habitus does not simply consist of two places and their connections, but comprises complex links across multiple borders (see McIlwaine 2012). Individuals’ migration, mobility and family histories, the ages at which they moved, and where they and their children formed their families influence the location and relationships people have with their close and extended kin -social capital. In turn, these factors also impact upon the availability of informal care capital, as well as practical support and care.

The transnational habitus of these middle class interviewees rests to great extent on their desire to continue mobility when retired. The international mobility and migration of ageing individuals is 
often not studied because studies on ageing usually rely on theoretical frameworks that emphasize continuity, and not disruption which migration is often assumed to entail (Torres and Karl 2016, 2). A transnational habitus at the time of retirement means that individuals imagine mobility and migration as being part of their lives when retired, if not physically, then at least psychologically. Physical mobility is only one type of transnationality, and memories, photos and letters allow nonbodily international mobility, made available by combining heterogeneous cultural references inherited from an individual's physical and virtual journeys (see Nedelcu 2012; Lean 2012). Both the physical and mental international mobility is at risk with an ailing body and mind, and illnesses, disabilities and memory disorders are more likely with increasing age. This means that changes in habitus are likely, particularly when an individual encounters unfamiliar fields such as illness, and social and healthcare services as a result. The ailing body and mind also experience a disorientation and reorientation similar to resettlement, which is the means through which people are able to redirect in relation to a new field. Retirement is such a new field for the interviewees of this study.

Personal history interacts with national policies on immigrants that determine their welfare entitlements such as pensions, travel and residence permits, income benefits, and access to health and social services. These policies may either create barriers or open possibilities regarding decisions on retirement locations for transnational individuals. The structural fields connected with the laws and policies on migration, mobility, pensions, social services and healthcare are changing. New policies allow and restrict mobility in new ways, for example by influencing the transferability of benefits and accessibility to services. Transnational retirees attach and detach themselves from these benefits and services, depending on their mobility, citizenship status, levels of capital and individual needs. In this setting, social networks or social capital are likely to be less influential, while health, wealth, and current and deferred income (or pension) endowments are central to the wellbeing of transnational individuals living in their third or fourth age (cf. Warnes et al. 2004, 
313). It has been claimed that local class, gender and regional inequalities are transformed into transnational class, gender and regional inequalities (Guarnizo 1997, 312). Similarly, the privileges of middle class migrants have the potential to become transnational privileges, although when the field changes, the value of the capitals involved may wither. What appears to be a generous pension from one country may be meagre in another.

The diminishment of migrant capital has often been studied by focusing on migrants who initially moved from a less developed country to a more developed or wealthier one, and considered returning at the age of retirement. The participants in this study migrated between wealthy Western countries, and yet still faced the risk that some of their accumulated capital would diminish, firstly on retirement, and secondly with migration. However, the amount of capital is not the only asset in the context of transnational fields, but rather how they are combined and the skill with which they are used.

\section{References}

Ackers, Louise and Peter Dwyer. 2002. Senior Citizenship?: Retirement, Migration and Welfare in the European Union. Bristol: The Policy Press.

Allan, Kenneth. 2007. The Social Lens. An Invitation to Social and Sociological Theory. Thousand Oaks: Sage Publications.

American Government page on health insurances. Available at shttps://www.usa.gov/healthinsurance, Accessed January 23, 2017.

Anttonen, Anneli and Jorma Sipilä. 2006. “Care Capital, Stress and Satisfaction.” In Women, Work and Family in Europe, edited by Rosemary Crompton, Suzan Lewis and Clare Lyonette, 222-249. Houndmills: Palgrave Macmillan. 
Attias-Donfut, Claudine. 2016. “Older Migrants’ Ageing and Dying. An Intergenerational Perspective.” In Ageing in Contexts of Migration edited by Ute Karl and Sandra Torres, 83-95. London: Routledge.

Bauder Harald. 2004. “Habitus, Rules of the Labour Market and Employment Strategies of Immigrants in Vancouver, Canada." Social and Cultural Geography 6(1)81-97.

Benson, Michaela. 2012. “How Culturally Significant Imaginings are Translated into Lifestyle Migration.” Journal of Ethnic and Migration Studies 38(10), 1681-1696.

Bolzman, Claudio, Rosita Fibbi, and Marine Vial. 2006. What to Do after Retirement? Elderly Migrants and the Question of Return. Journal of Ethnic and Migration Studies 32(8), 1359-1375. Bourdieu, Pierre. 1977. Outline of a Theory of Practice. London: Cambridge University Press. Bourdieu, Pierre. 1984. Distinction. A Social Critique of the Judgement of Taste. London: Routledge and Kegan Paul.

Bourdieu, Pierre. 1986. “The Forms of Capital.” In Handbook of Theory and Research in the Sociology of Education, edited by John Richardson, 241-258. New York: Greenwood Press. Bourdieu, Pierre. 1989. “Social Space and Symbolic Power.” Sociological Theory 7 (1): 14-25. Bourdieu, Pierre. 1990. The Logic of Practice. Stanford: Stanford University Press.

Brewer, William F. 1986. “What is Autobiographical Memory?” In Autobiographical Memory, edited by David C. Rubin, 25-49. Cambridge: Cambridge University Press.

Böcker, Anita \& Canan Balkir. 2016. “Maintaining Dual Residences to Manage Risks in Later Life. A Comparison of Two Groups of Older Migrants.” In Transnational Aging. Current Insights and Future Challenges edited by Vincent Horn and Cornelia Schweppe, 125-140. New York: Routledge.

Ciobanu, Ruxana Oana and Anne Carolina Ramos. (2016) “Is There a Way Back? A State-of-theart Review of the Literature on Retirement Return Migration.” In Ageing in the Contexts of Migration edited by Ute Karl and Sandra Torres, 96--107. London: Sage. 
Denzin, Norman K. 1989. Interpretive Interactionism. Newbury Park: Sage.

Fechter, Anne-Meike and Katie Walsh (2010) “Examining ‘expatriate’ continuities: Postcolonial approaches to mobile professionals.” Journal of Ethnic and Migration Studies 36(8), 1197-1210. Ferrell, Jeff (2012) “Autoethnography.” In The SAGE Handbook of Criminological Research Methods edited by David Gadd, Susanne Karstedt and Steven F Messner, 218-230. London: Sage. Fokkema, Tineke, Eralba Cela, and Witter Yvonne. 2016. 'Pendular Migration of the Older Generations in Europe.” In Transnational Aging. Current Insights and Future Challenges edited by Vincent Horn and Cornelia Schweppe, 141-159. New York: Routledge.

Gardner, Katy. 2002. Age, Narrative and Migration. The Life Course and Life Histories of Bengali Elders in London. Oxford: Berg.

Gilleard, Chris and Paul Higgs. 2005. Contexts of Ageing: Class, Cohort and Community. Cambridge: Polity Press.

Gerhards, Jürgen and Silke Hans. 2013. “Transnational Human Capital, Education, and Social Inequality. Analyses of International Student Exchange.” Zeitschrift für Soziologie 42(2): 99-117. Guarnizo Luis, Eduardo. 1997. “The Emergence of a Transnational Social Formation and the Mirage of Return Migration among Dominican Transmigrants.“ Identities 4(2): 281-322.

Gupta, Akhil and James Ferguson. 1992. "Beyond "Culture": Space, identity, and the Politics of Difference.” Cultural Anthropology 7 (1): 6-23.

Hall, C. Michael and Alan M. Williams. (eds.) 2002. Tourism and Migration: New Relationships between Production and Consumption. Dordrecht: Springer.

Himmelreicher, Ralf and Wolfgang Keck. 2016. “Transnational Aging as Reflected in Germany’s Pension Insurance.” In Transnational Aging. Current Insights and Future Challenges edited by Vincent Horn and Cornelia Schweppe, 107-125. New York: Routledge.

Horn, Vincent, Cornelia Schweppe, Désirée Bender, and Tina Hollstein. 2016. “"Moving (for) Elder Care Abroad": The Fragile Promises of Old-Age Care Facilities for Elderly Germans in 
Thailand.” In Transnational Aging. Current Insights and Future Challenges edited by Vincent Horn and Cornelia Schweppe, 163-177. New York: Routledge.

Hugo, Graeme. 2013. What We Know About Circular Migration and Enhanced Mobility. Policy Brief No. 7. Washington D.C.: Migration Policy Institute.

Karl, Ute and Anne Carolina Ramos. 2016. “Migrants’ post-retirement practices. A Migratory lifecourse approach to the study of work.” In Ageing in Contexts of Migration edited by Ute Karl and Sandra Torres, 119-132. London: Routledge.

Kelly, Philip and Tom Lusis. 2006. "Migration and the Transnational Habitus: Evidence from Canada and the Philippines.” Environment and Planning 38 (5): 831-847.

King, Russell. 2012. “Geography and Migration Studies: Retrospect and Prospect.” Population, Space and Place 18 (2): 134-153.

Klinthäll, Martin. 2014. “Older Immigrants Leaving Sweden.” In Return Migration in Later Life. International Perspectives, edited by John Percival, 21-42. Bristol: Policy Press.

Lean, Garth. 2012. “The Lingering Moment.” In The Cultural Moment in Tourism edited by Laurajane Smith, Emma Waterton and Steve Watson, 274-291. Abingdon: Routledge.

McIlwaine, Cathy. 2012. “Constructing Transnational Social Spaces among Latin American Migrants in Europe: Perspectives from the UK.” Cambridge Journal of Regions, Economy and Society 5(2): 289-304.

Nedelcu, Mihaela. 2012. “Migrants’ New Transnational Habitus: Rethinking Migration Through a Cosmopolitan Lens in the Digital Age.” Journal of Ethnic and Migration Studies 38(9): 1339-1356. Nukaga, Misako. 2012. “Planning for a Successful Return Home: Transnational Habitus and Education Strategies among Japanese Expatriate Mothers in Los Angeles. International Sociology 28(1) 66-83. 
O’Reilly, Karen. 2002. “Britain in Europe/The British in Spain: Exploring Britain’s Changing

Relationship to the Other through the Attitudes of Its’ Emigrants.” Nations and Nationalism 8 (2), $179-193$.

O’Reilly, Karen. 2014. "The Role of the Social Imaginary in Lifestyle Migration: Employing the Ontology of Practice Theory.” In Understanding Lifestyle Migration. Theoretical Approaches to Migration and the Quest for Better Life edited by Michaela Benson and Nick Osbaldiston, 211-234. Houndmills: Palgrave Macmillan.

Parker, David. 2000. “The Chinese Takeaway and the Diasporic Habitus: Space, Time, and Power Geometries.” In Un/Settled Multiculturalisms edited by Barnor Hesse, 73-95. London: Zed Books. Reynolds, Tracey and Elisabetta Zontini. 2014. “Transnational Families: Migrant Youths 'Doing' Families across Proximities and Distances.” Families, Relationships and Societies 3(2) 251-268. Richardson, Chris and Hans A. Skott-Myhre. 2012. “Introduction.” In Habitus of the Hood edited by Chris Richardson and Hans A. Skott-Myhre, 7-26. Bristol: Intellect.

Skeggs, Beverly. 2004. Class, Culture, Self. London: Routledge.

Torres, Sandra and Ute Karl. 2016. “A Migration Lens on Inquiries into Ageing, Old Age and Elderly Care. Carving a Space while Assessing the State of Affairs.” In Ageing in Contexts of Migration edited by Ute Karl and Sandra Torres, 1-12. Abingdon: Routledge.

Vertovec, Steven. 2009. Transnationalism. London: Routledge.

Warnes, Anthony, M., Klaus Friedrich, Leonie Kellaher, and Sandra Torres. 2004. The diversity and welfare of older migrants in Europe. Ageing \& Society 24(3): 307-326.

White, Rob and Joanna Wyn. 2004. Youth and Society: Exploring the Social Dynamics of Youth Experience. Melbourne: Oxford University Press.

Zechner, Minna. 2008. Care of older persons in transnational settings. Journal of Aging Studies 22(1): $32-44$. 
Zechner, Minna. 2010. “Global care and national social policies.” In Global care work. Gender and migration in Nordic societies edited by Lise Widding Isaksen, 175-198. Lund: Nordic Academic Press. 